\title{
Trend and Abrupt Analysis of Rainfall Change During Last 50 Years in the WeiHe Basin
}

\author{
Li Zhi, Sun Dongyong \\ School of Environmental Science and Engineering, Chang'an University, Xi'an, China
}

\section{Email address:}

lzconstantine@163.com (Li Zhi)

\section{To cite this article:}

Li Zhi, Sun Dongyong. Trend and Abrupt Analysis of Rainfall Change During Last 50 Years in the WeiHe Basin. Earth Sciences. Vol. 4, No. 6, 2015, pp. 228-234. doi: 10.11648/j.earth.20150406.12

\begin{abstract}
In order to explore the change of 50 years' rainfall trend and abrupt change in WeiHe Basin, we using the annual rainfall data of 21 important control stations in WeiHe basin from 1960 to 2012 to analyze the changes in the time rainfall and the change trend of the annual rainfall anomaly, and using Kendall - Mann method to test the trend of rainfall in WeiHe Basin. It shows that rainfall rate keeps decreasing during the last 50 years, and the change rate of upstream is generally greater than the midstream and downstream. For mutation years, it occurs in 1970s in downstream, in1970s and 1980s in midstream and in 1990s and after 2000 in upstream. It shows that the change of rainfall in different regions have different performance. From the tendency analysis, we can predict that the whole WeiHe basin will keep a decreasing trend of annual rainfall in the future.
\end{abstract}

Keywords: WeiHe Basin, Tendency Analysis of Precipitation, Mann-Kendall, Abrupt Analysis

\section{Introduction}

Rainfall is the fundamental source of runoff. Runoff is influenced by climatic, underlying surface conditions and human activities. Rainfall is the main factor that influence flow changes and human activities in basin, studying spatial-temporal distribution features of rainfall will be of great importance to understand drought climate changes, also it can provide climatic basis for drought-flood control, and estimate the hydrological environment of the basin [1-3].

There are many methods to analyze the tendency, such as cumulative anomaly method, sliding average test and Mann-Kendall method etc. When the change of sequence trend becomes more obvious, tendency can be intuitive judged by using cumulative anomaly method and the maps of the change curve. While, when there is no obvious trend change, this intuitive judgment is not reliable. So we need to use statistic methods such as Mann-Kendall test and sliding t test to solve the problem. In recent years, many scholars have done a lot of research on the analysis of the hydrological and meteorological trends. Such as Chen et al. applied cumulative filter and rank correlation method to analysis the changes of the meteorological hydrological sequence in the Gansu Hexi region in last 50 years [4]; Qin et al. chosen Yangtze River Basin stations, by applications of 1882 2000 years', 1870 2000 years' and 1950-2000 years' average monthly flow data and decadal, monthly and seasonal changes in runoff and runoff change trend, using the Mann-Kendall non parameter method to test the runoff trend [5]; Peng et al. using a linear regression equation to analyze the recent 50 years' rainfall characteristics on Jing He, Wei He and Luo He of the middle reaches of the Yellow River [6]. In the above researches, the tendency test methods are based on parameter estimation to obtain the characteristics of rainfall variation in the study area. While the non-parametric test method is more suitable for the test of non-normal distribution in the hydrological and meteorological time series. As a result, the Mann-Kendall method of non- parametric test is wildly used to analyze the precipitation trend of a river basin, then the linear regression method is used to verify the results [7-10]. For example, Wang et al. using Mann - Kendall method and regression analysis to examine the long-term variation of annual rainfall in Shapotou area [11]. Jiao et al. selected the temperature and precipitation data of 6 stations in Jiuquan during 1959 2008 to analyze the characteristics of climate change in the region using moving average and Mann-Kendall method. The results show that: in the background of global warming, the temperature change of Jiuquan city is obvious, but the precipitation rate is not [12]. Based on scaling assumptions, Hamed used Mann-Kendall method to analyzed the trend of the regional rainfall [13]. Xu et al. analyzed annual rainfall in the Yellow River basin by Mann-Kendall method, it shows that over the past 50 years, the rainfall of whole area has a 
downward trend, but it can't predict the trend [14]. They both show that the Kendall - Mann method can reveal the tendency of the time series well.

\section{Trend Analysis Method}

\subsection{Cumulative Anomaly Method}

In the method of judging the changing trend, the Cumulative anomaly method is a more common method. At a certain moment $t$, The cumulative anomaly of hydrological sequence of samples $x_{1}, x_{2}, x_{3}, \cdots, x_{n}$, expressed as:

$$
S_{t}=\sum_{i=1}^{t}\left(x_{i}-\bar{x}\right), \quad \bar{x}=\frac{1}{n} \sum_{i=1}^{n} x_{1}
$$

Plotting $S_{t}$-t curve, can be analyzed according to the change trend curve.

\subsection{Sliding $t$ Test}

Selecting randomly one year of known annual runoff sample sequences $x_{1}, x_{2}, x_{3}, \cdots, x_{n}$, The annual runoff of $n_{1}$ consecutive years before it and $n_{2}$ consecutive years after it were selected.

$$
\begin{gathered}
T=\frac{\overline{x_{1}}-\overline{x_{2}}}{S \sqrt{\frac{1}{n_{1}}-\frac{1}{n_{2}}}} \\
S=\sqrt{\frac{\left(n_{1}-1\right) s_{1}^{2}+\left(n_{2}-1\right) s_{1}^{2}}{n_{1}+n_{2}-2}}
\end{gathered}
$$

Which: $x_{1}, s_{1}$ the mean and variance for $n_{1}$ years ago; $\overline{x_{2}}, S_{2}$ the mean and variance for $n_{1}$ years ago.

After the $\mathrm{T}$ value is calculated, testing the credibility.

\subsection{Mann-Kendall Test}

Mann-Kendall test does not require the sample to comply with a certain distribution, suit for hydrological, meteorological, and other non-normal distribution's data, and it is not affected by the number of abnormal value [15].

Original hypothesis $H_{0}$ is time series data $\left(x_{1}, x_{2}\right.$, $\left.x_{3}, \cdots, x_{n}\right)$, are $\mathrm{n}$ independent, random variables with the distribution of the sample; alternative hypothesis $H_{1}$ is bilateral inspection, for all $\mathrm{k}, \mathrm{j} \leqq \mathrm{n}$, and $k \neq \mathrm{j}$, the distribution of $x_{h}$ and $x_{j}$ is different, statistical variable $\mathrm{S}$ is calculated as follows:

$$
S=\sum_{k=1}^{n-1} \sum_{j=k+1}^{n} \operatorname{Sgn}\left(x_{j}-x_{h}\right)
$$

Which:

$$
\operatorname{Sgn}\left(x_{j}-x_{h}\right)=\left\{\begin{array}{cc}
+1 & \left(x_{j}-x_{h}\right)>0 \\
0 & \left(x_{j}-x_{h}\right)=0 \\
-1 & \left(x_{j}-x_{h}\right)<0
\end{array}\right\}
$$

$\mathrm{S}$ is normal distribution, mean value is 0 .Variance $\operatorname{V\alpha r}(s)=n(n-1)(2 n+5) / 18$, when $\mathrm{n}>10$, The standard normal statistical variables are calculated by the following:

$$
Z=\left\{\begin{array}{cc}
\frac{s-1}{\sqrt{V \alpha r(s)}} & s>0 \\
0 & s=0 \\
\frac{s+1}{\sqrt{V \alpha r(s)}} & s<0
\end{array}\right\}
$$

In this way, in the bilateral trend test, at a given confidence level $\alpha$, if $|Z| \geq Z_{1-\alpha / 2}$, The original hypothesis is unacceptable. At the $\alpha$ confidence level, the time series data exist obvious rise or fall trend. For Statistical variable $Z$, when $\mathrm{Z}>0$, it is upward trend; when $\mathrm{Z}<0$, it is downward trend. When absolute value of $Z$ greater than or equal 1.28 , 1.64 and 2.32 , it indicates that the significance test of $95 \%$, $90 \%$ and $99 \%$ was adopted.

When the Mann-Kendall test is used to test the sequence mutation, the test statistic is different from that of the $\mathrm{Z}$, by constructing a rank sequence:

$$
S_{k}=\sum_{i=1}^{k} \sum_{j}^{j-1} \alpha_{i j} \quad(\mathrm{k}=1,2, \ldots \mathrm{n})
$$

which, $\quad \alpha_{i j}=\left\{\begin{array}{ll}1 & x_{i}>x_{j} \\ 0 & x_{i} \leq x_{j}\end{array}\right\} \quad 1 \leq j \leq i$

Defining statistical variables:

$$
U F=\frac{\left[S_{k}-E\left(S_{k}\right)\right]}{\sqrt{\operatorname{V\alpha r}\left(S_{k}\right)}}(\mathrm{k}=1,2, \ldots \mathrm{n})
$$

when $E\left(S_{h}\right)=k(K+1) / 4$; $\operatorname{V\alpha r}\left(S_{k}\right)=k(k-1)(2 k+5) / 72$

UF is a standard normal distribution, given the level of significance $\alpha$, if $\left|U_{f}\right|>U_{\alpha / 2}$, it shows that the sequence has obvious trend change.

$$
\left\{\begin{array}{l}
U B_{k}=-U F_{k} \\
k=n+1-k
\end{array} \quad(\mathrm{k}=1,2, \ldots \mathrm{n})\right.
$$

The trend of X can be further analyzed by analyzing UF and $\mathrm{UB}$, then the time of mutation can be defined, and pointing out the region of the mutation. If the UF value is greater than 0 , the sequence is on the rise, If the UF value is less than 0 , it shows a downward trend. When they exceed the critical line, it shows that the rise or fall of the trend is significant. If UF and UB have intersection points during the critical line, then the point of intersection is the beginning of the abrupt. 


\section{General Situation of WeiHe River Basin}

Weihe, Weiyuan County, Gansu Province, is the largest tributary of the Yellow River, flows through Gansu, Ningxia, Shaanxi provinces 26 counties and cities, to Shaanxi into the Yellow River, the basin area of $134800 \mathrm{~km} 2$.River length of $818 \mathrm{~km}$, Baoji Gorge above for upstream, river long $430 \mathrm{~km}$, it has narrow riverway and fast flowing; Baoji Gorge to Xianyang for the middle, $180 \mathrm{~km}$ long river, river wider, more sand and water dispersion; Xianyang into Huangkou downstream, the river is $208 \mathrm{~km}$, than smaller drop, flow is slow. Rainfall distribution from the southeast to the northwest descending, southern Qinling Piedmont rainfall abundant, maximum annual rainfall in $1000 \mathrm{~mm}$ above, with the terrain reduced rainfall plummeted, plain areas annual rainfall about $500 \mathrm{~mm}$. The annual variation of rainfall is great and the distribution of the year is nonuniform. The maximum annual rainfall is about 2.5 times than the minimum annual rainfall, and the rainfall of flood season is about $65 \%$ of the annual rainfall. [16] The Weihe Basin is as follow:

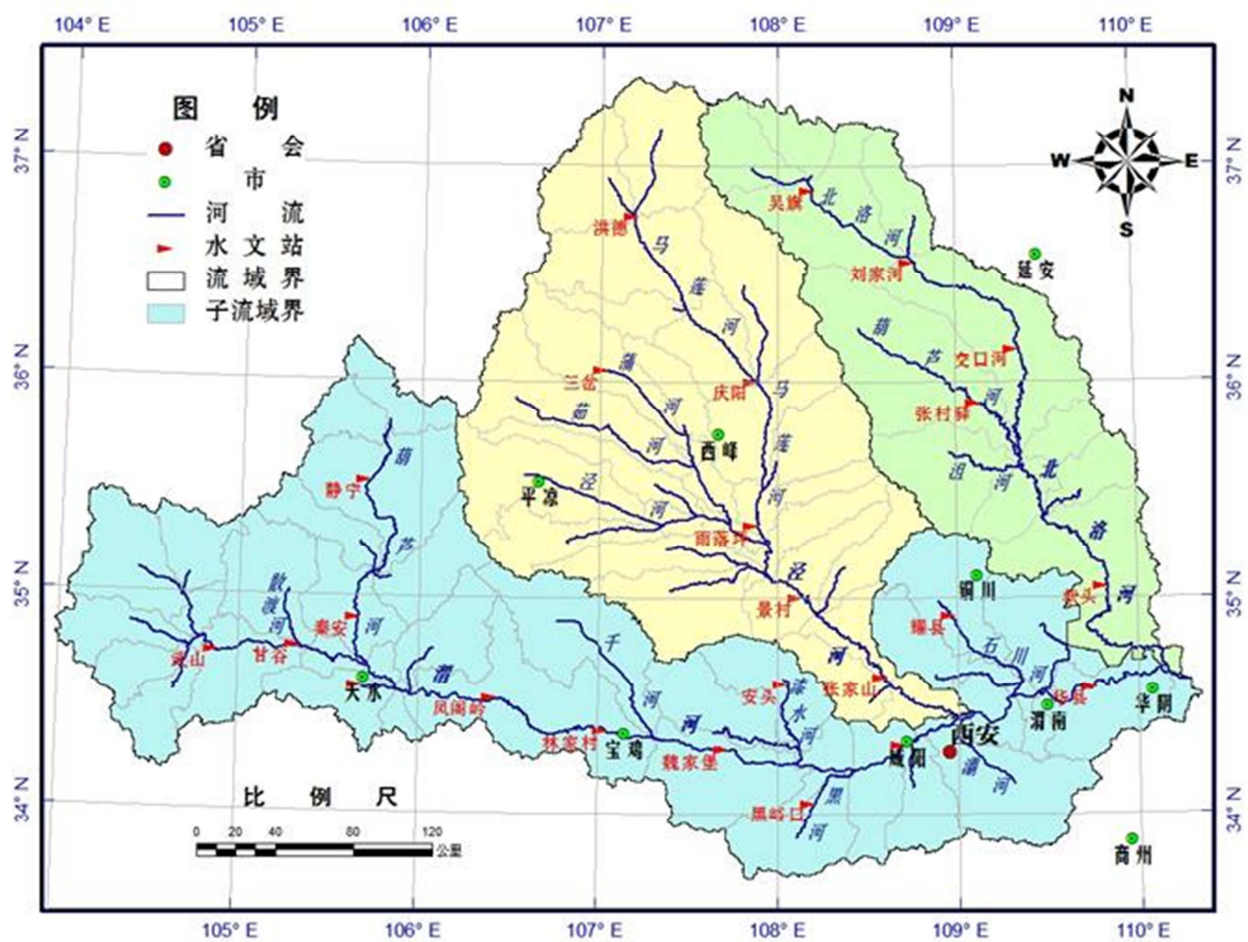

Figure 1. WeiHe Basin.

This paper analyzed the rainfall data of TianShui, WuGong, Baoji hydrological station of WeiHe Basin.

\section{Results and Discussion}

\subsection{Annual Rainfall Interdecadal Change}

The anomaly can be used to reflect the hydrological data relative to the period of a long-term average is high or low. We choose PingLiang, ShangZhou and HuaShan station in WeiHe Basin as an example. From the change of time, in the 1960s and 1970s, the anomaly from the Pingliang Station is position, it indicate annual average precipitation is increased; it is negative after 1980s, it indicate annual average precipitation is reduced (see Table 1). ShangZhou station in 1960s, 1980s and 2000 s average annual precipitation increased, remaining in less precipitation (see Table 2). HuaShan station 1960s 1980s rainfall increased, the amount of rainfall after the 1980s years decreased significantly (see Table 3). Overall, WeiHe Basin in interdecadal rainfall from the 1960 2012 first increased and then decrease, 1960s and 1970s years increased significantly, after 2000 it is significantly reduced, which in lower reaches of the reflected the most obvious.

Table 1. Interdecadal rainfall and anomaly of PingLiang station.

\begin{tabular}{lll}
\hline Times & Rainfall & Anomaly \\
\hline $1960 \mathrm{~s}$ & 558.89 & 64.85 \\
$1970 \mathrm{~s}$ & 494.37 & 0.33 \\
$1980 \mathrm{~s}$ & 484.56 & -9.48 \\
$1990 \mathrm{~s}$ & 485.89 & -8.15 \\
$2000 \mathrm{~s}$ & 457.04 & -37.00 \\
After 2010 & 458.80 & -35.24 \\
\hline
\end{tabular}

Table 2. Interdecadal rainfall and anomaly of ShangZhou station.

\begin{tabular}{lll}
\hline Times & Rainfall & Anomaly \\
\hline $1960 \mathrm{~s}$ & 719.97 & 36.93 \\
$1970 \mathrm{~s}$ & 656.89 & -26.15 \\
$1980 \mathrm{~s}$ & 754.75 & 71.71 \\
$1990 \mathrm{~s}$ & 604.28 & -78.76 \\
$2000 \mathrm{~s}$ & 697.01 & 13.97 \\
After 2010 & 624.00 & -59.04 \\
\hline
\end{tabular}


Table 3. Interdecadal rainfall and anomaly of HuaShan station.

\begin{tabular}{lll}
\hline Times & Rainfall & Anomaly \\
\hline $1960 \mathrm{~s}$ & 879.38 & 70.92 \\
$1970 \mathrm{~s}$ & 875.97 & 67.51 \\
$1980 \mathrm{~s}$ & 888.63 & 80.17 \\
$1990 \mathrm{~s}$ & 701.15 & -107.31 \\
$2000 \mathrm{~s}$ & 717.86 & -90.60 \\
After 2010 & 739.53 & -68.93 \\
\hline
\end{tabular}

\subsection{Linear Trend Test}

In the last few decades, the rainfall in China has decreased, but it has obvious regional style. The change trend plots of the annual rainfall anomaly between WuGong station and BaoJi station in the 21 stations of basin in WeiHe basin is given below:

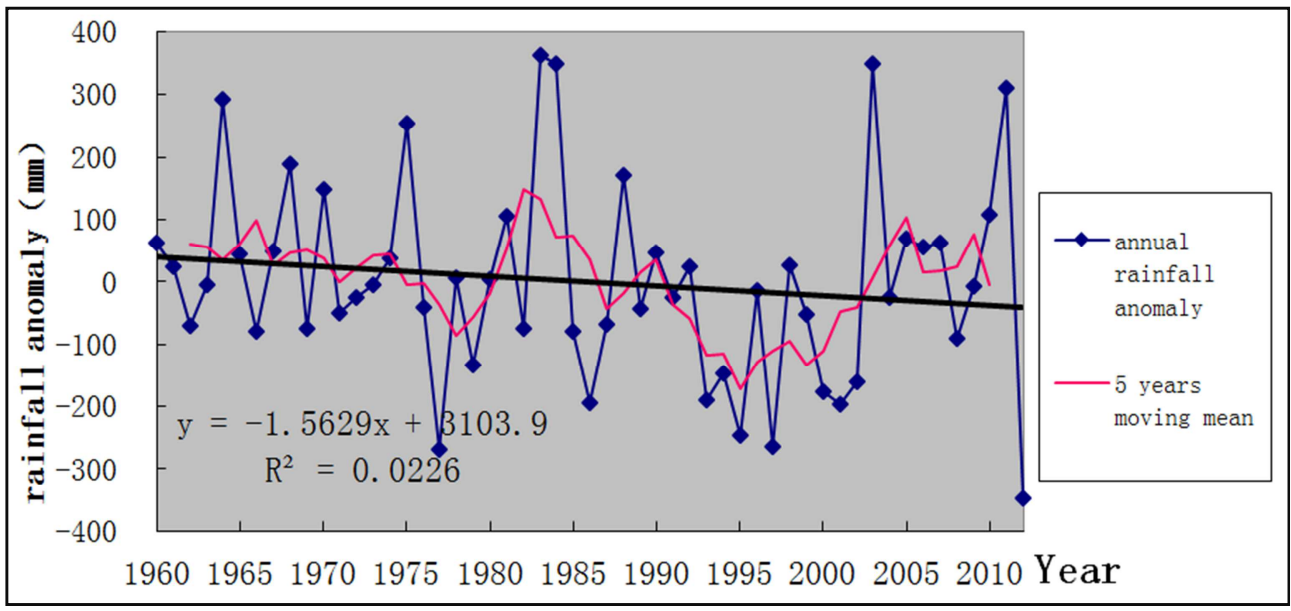

Figure 2. Plot of change trend of annual rainfall anomaly of WuGong station.

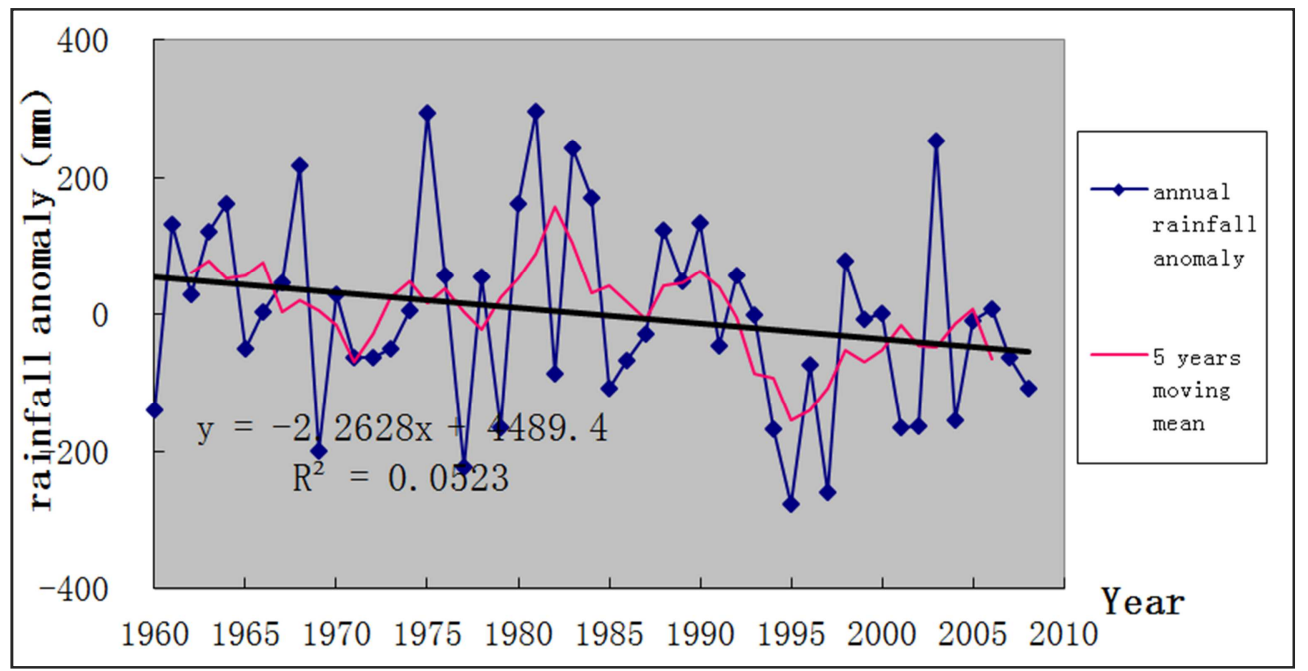

Figure 3. Plot of change trend of annual rainfall anomaly of BaoJi station.

In the WeiHe basin, the change trend of the rainfall anomalies in the 1960 2012 of the 21 stations are summarized as follows:

Table 4. Changing trend of annual rainfall anomalies in the WeiHe River Basin from 21 stations.

\begin{tabular}{llllllll}
\hline Station & Slope & $\mathbf{R}^{2}$ & Trend & Station & Slope & $\mathbf{R}^{2}$ & Trend \\
\hline BaoJi & -2.2628 & 0.0523 & drop & Zhen'an & -0.8578 & 0.0054 & drop \\
FoPing & -1.6023 & 0.0175 & drop & XiJQi & -2.2874 & 0.1459 & drop \\
HuaShan & -4.5531 & 0.1658 & drop & GuYuan & -2.477 & 0.129 & drop \\
LuoChuan & -1.5677 & 0.032 & drop & XiFeng & -1.9953 & 0.0618 & drop \\
ShangZhou & -1.296 & 0.0156 & drop & TianShui & -1.8652 & 0.036 & drop \\
TongChuan & -0.7507 & 0.0054 & drop & PinLiang & -2.0589 & 0.0724 & drop \\
WuQi & -1.5179 & 0.0431 & drop & MinXian & -2.2205 & 0.127 & drop \\
WuGong & -1.5629 & 0.0226 & drop & LinTao & -2.7439 & 0.1426 & drop \\
Xi'an & -0.685 & 0.0065 & drop & HuanXian & -1.9964 & 0.0677 & drop \\
Yan'an & -2.5759 & 0.107 & drop & HuaJiaLing & -2.7259 & 0.1427 & drop \\
ChangWu & -1.0709 & 0.0145 & drop & & & & \\
\hline
\end{tabular}


In conclusion, 1960 2012 years' annual rainfall in WeiHe basin is reduced. Due to geographical differences, change rate of upstream is generally greater than the midstream and downstream, and the slopes of the Tongchuan, Xi'an and Zhen'an are more than -1 , it indicates the annual rainfall variation trend in these areas is generally small. The slopes of Huashan, Yan'an, Lintao and Huajialin are less than -2.5 , it indicates that the annual rainfall variation trend in these areas is generally great. From the change trend of annual rainfall anomaly in the WeiHe River Basin, the rainfall in WeiHe basin is generally decreased, due to the regional differences, the change rate of upstream is larger than the middle and lower reaches. The difference of these changes is mainly due to the impact of climate change in different regions of WeiHe basin during the decades, and the intensity of human activities.

\subsection{Mann-Kendall Test}

Mann-Kendall method is a common non parametric test method in the world [17-21]. The rainfall trend analysis of several stations in the 21 stations in WeiHe river basin is shown as follows, Blue dot labeled line indicates UF value, The red square shaped mark line represents the UB value.

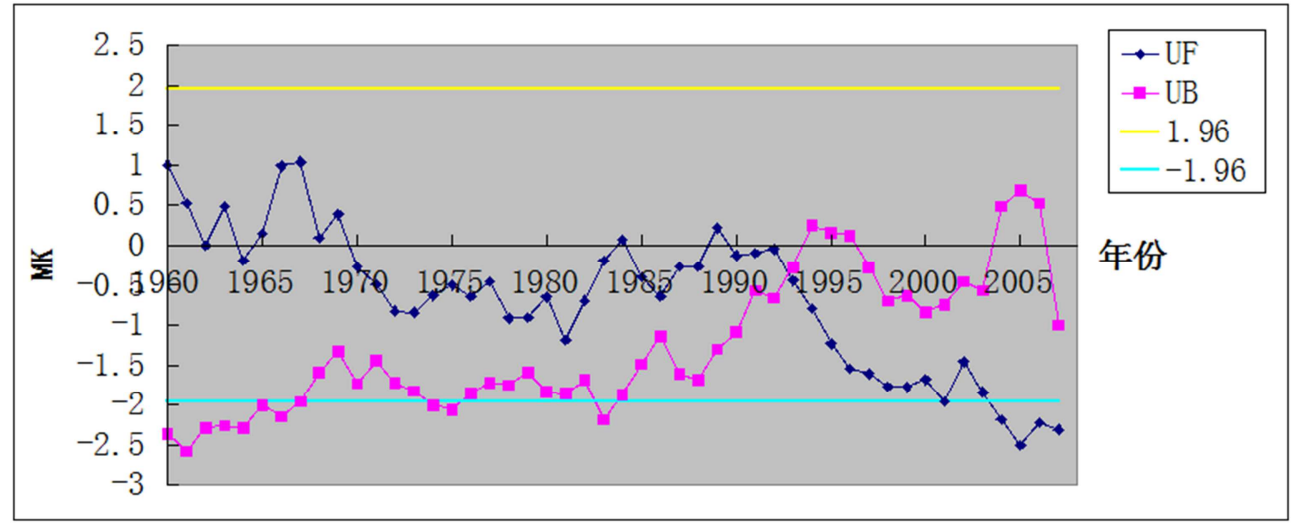

Figure 4. MK change trend of annual average rainfall in TianShui station.

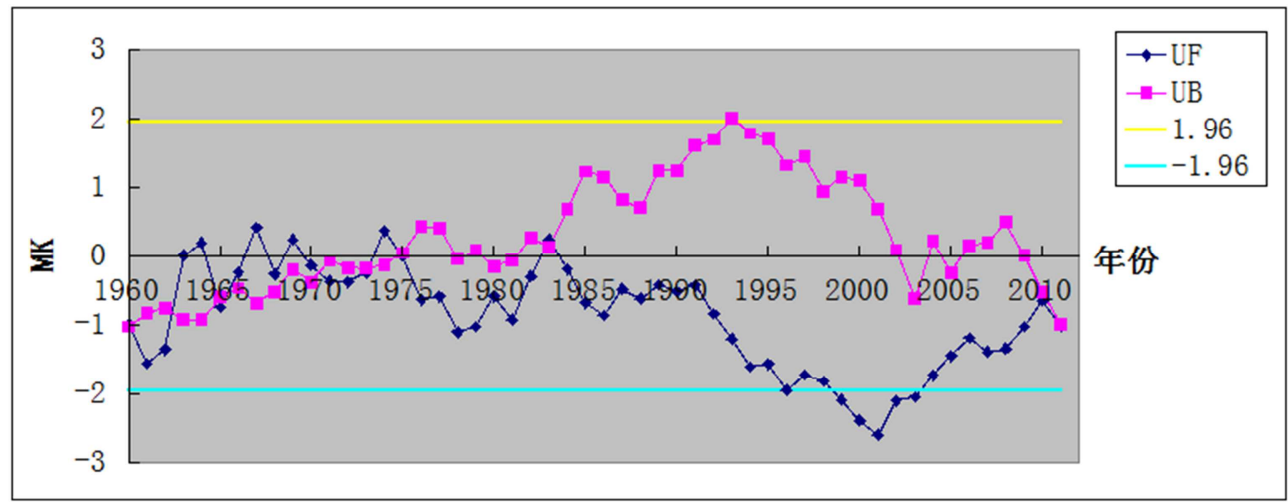

Figure 5. MK change trend of annual average rainfall in WuGong station.

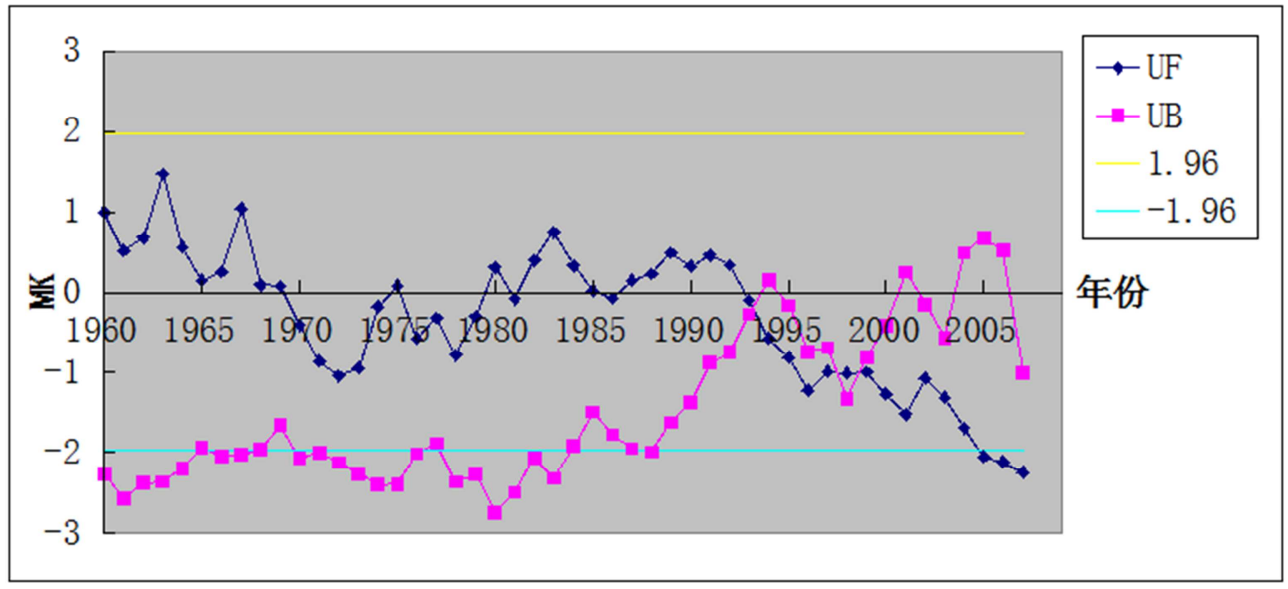

Figure 6. MK change trend of annual average rainfall in BaoJistation. 


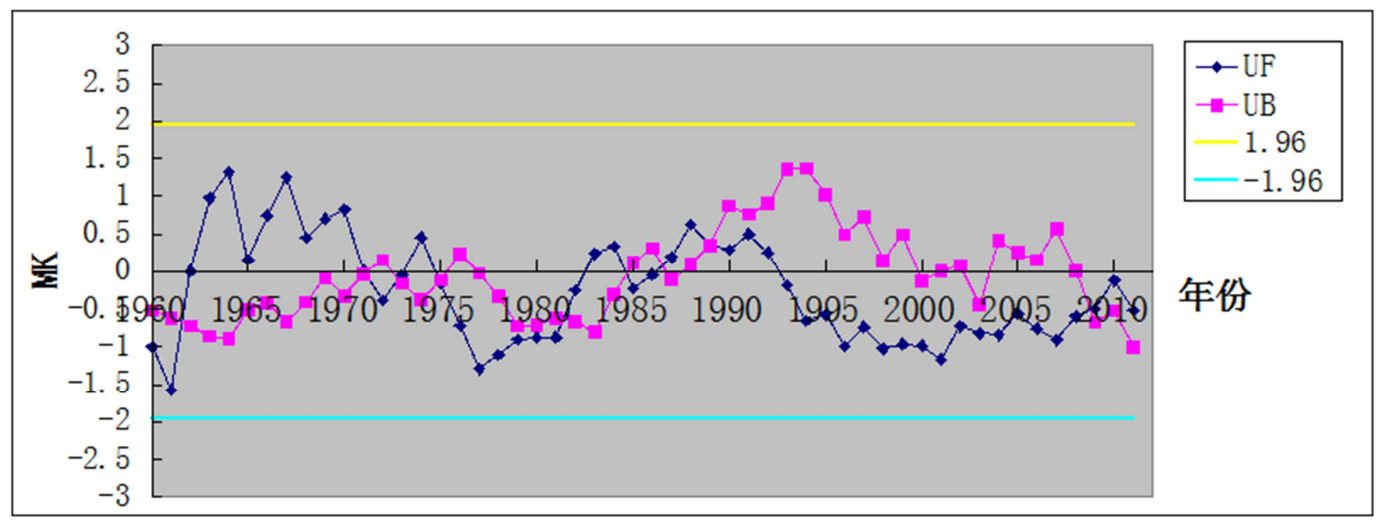

Figure 7. MK change trend of annual average rainfall in ShangZhou station.

Take Figure 5 and Figure 6 as an example, the total rainfall of 1960 2012 in WuGong station is decreasing, UF value of 1960 1963, 1965 1966, 1968, 1970 1973, 1976 1982 and 1984 2012 are less than 0, it indicates that rainfall is decreased, which 1999 2003 MK values are more than a significant level of $\alpha=0.05$. The rainfall in the other years was increased, but it had no significant level of $\alpha=0.05$. Annual rainfall abrupt years are 1962, 1965, 1970, 1973, 1975, 1983and2011.The total rainfall of 1960 2008 in BaoJi station is decreasing, UF value of 1970 1974, 1976 1979, 1985, 1993 2008 are less than 0, it indicates that rainfall is decreased, which 2005 2008 MK values are more than a significant level of $\alpha=0.05$. The rainfall in the other years was increased, but it had no significant level of $\alpha=0.05$. Annual rainfall abrupt years are 1993, 1997and1999.

In the WeiHe basin, the decrease trend of the rainfall and abrupt years in the 1960 2012 of the 21 stations is summarized as follows:

Table 5. The summary of trend changes and abrupt years of the 21 stations in WeiHe basin.

\begin{tabular}{|c|c|c|}
\hline Station & Abrupt & Trend \\
\hline BaoJi & 1993、1997、1999 & Drop \\
\hline FoPing & $\begin{array}{l}\text { 1968、1972、1976、1978、1985、1989、201 } \\
0\end{array}$ & Drop \\
\hline HuaShan & 1988 & Drop \\
\hline HuoChuan & $\begin{array}{l}\text { 1970、1974、1976、1977、1980、1982、198 } \\
\text { 4、2011 }\end{array}$ & Drop \\
\hline ShangZhou & $\begin{array}{l}\text { 1963、1971、1973、1975、1981、1984、198 } \\
6 、 1989 、 2008\end{array}$ & Drop \\
\hline TongChuan & 1999 & Drop \\
\hline WuQi & $\begin{array}{l}\text { 1970、1971、1981、1982、1985、1987、199 } \\
\text { 1、1995、1997、1998、1999、2003、2005、 } \\
\text { 2007、2008、2009 }\end{array}$ & Drop \\
\hline WuGong & $\begin{array}{l}\text { 1962、1965、1970、1973、1975、1983、201 } \\
1\end{array}$ & Drop \\
\hline Xi'an & $\begin{array}{l}1965-1968 、 1970 、 1973 、 1975 、 1981 、 198 \\
\text { 4、1986、1988 }\end{array}$ & Drop \\
\hline Yan'an & 1979、1984 & Drop \\
\hline ChangWu & 1979、1984、1986、1989、2009 & Drop \\
\hline Zhen'an & $\begin{array}{l}\text { 1967、1969、1986、1975、1977、1985、198 } \\
\text { 8、2009 }\end{array}$ & Drop \\
\hline XiJi & 2006 & Drop \\
\hline GuYuan & 1997、1998、1999、2000、2003 & Drop \\
\hline XiFeng & $\begin{array}{l}\text { 1971、1978、1981、1982、1984、1989、200 } \\
1 、 2003\end{array}$ & Drop \\
\hline
\end{tabular}

\begin{tabular}{llll}
\hline Station & Abrupt & Trend \\
\hline TianShui & 1993 & Drop \\
PingLiang & 1971、1985、1988、1990、1991、1993、199 & Drop \\
6inXian & 1986、1998、2000、2004、2008 & \\
LinTao & 1981、1985、1986、1990、2002、2004、200 & Drop \\
6uanXian & 1970、2007 & Drop \\
HuJiaLing & 1986 & Drop \\
\hline
\end{tabular}

The table shows that the rainfall in the WeiHe basin in the 1960 2012 year is in a downward trend, which is consistent with the conclusion of the table 2, in which the MK value of the downstream of the WeiHe River Basin from the beginning of 1990s has a significantly decline, MK in the midstream has the overall decline but little fluctuation, the trend of rainfall in the upstream is most obvious; The abrupt years in the downstream always occurred on the 1970s or the 1980s, 1970s and $1980 \mathrm{~s}$ for midstream, about 2000 for upstream. It indicates that the Mann-Kendall test method can better reflect the trend of the hydrological factors and the abrupt year.

\section{Conclusion}

Based on the statistical analysis of the basic characteristics of 21 important hydrological stations in the WeiHe Basin, the paper used the annual rainfall anomaly analysis method and Mann-Kendall method to study the temporal-spatial change process and the law of rainfall in the basin. By analyzing the temporal-spatial variation of rainfall, the prediction of rainfall change in WeiHe basin will be more accurate in the future, also this will provide an important basis for rational development and utilization for water resources in basin.

The main research results are as follows:

(1) Through the analysis of the precipitation and anomaly of the 21 stations in WeiHe basin, the results shows that ten-year's rainfall rate in WeiHe Basin from the 1960 2012 increase at first and then decrease, which increased significantly between 1960s and 1970s, while there is a significant decrease after 2000.

(2) Plotting of the change trend of annual rainfall anomaly in different stations. It shows that between 1960 2012, annual rainfall in WeiHe basin is reduced, while the change rate in upstream is generally greater than in the midstream and 
downstream, the slopes of Tongchuan, Xi'an and Zhen'an are more than -1 , it indicates that the annual rainfall variation trend in these areas is generally small. The slopes of Huashan, Yan'an, Lintao and Huajialin are less than -2.5 , it means that the annual rainfall variation trend in these areas is obvious.

(3) The tendency of annual rainfall of 21 stations in WeiHe River Basin was analyzed by Mann-Kendall test. It indicates that the rainfall in the WeiHe basin between 1960 2012 has a downward trend, in which the trend of BaoJi, HuaShan, TongChuan, Yan'an, XiJi, GuYuan, Tianshui, Minxian, Lintao HuanXian and HuaJiaLing have exceeded the level significantly. For abrupt years, it occurs in 1970s in downstream, in1970s and 1980s in midstream and in 1990s and after 2000 in upstream.

(4) Analyzing the tendency of rainfall, we can predict that the whole WeiHe basin's annual rainfall will have a decreasing trend. This is possibly because of the global climate changing, and the intensification of human activities in this place.

\section{References}

[1] Neng Shi, Luweng Chen. Annual precipitation fields secular variation over global land areas for 1948-2000[J]. Chinese Science Bulletin, 2003, 43(3):281-286.

[2] Chen Genfa, Zhang Wanxia, Qin Dayong. Research progress of rainfall [A]. China Population, Resources and Environment, 2008, 18:3.

[3] Sheng Yue, Paul Pilon, George Cavadias. Power of the MannKendall and Spearman's rho tests for detecting monotonic trends in hydrological series [J]. Journal of Hydrology, 2002, 2:591.

[4] CHEN Ren-sheng, KANG Er-si, YANG Jian-ping et al. Variance tendency in the 50-year annual meteorological and hydrological series of Hexi region of Gansu Province[J].Journal of Lanzhou University(Natural Sciences) ,2002,02:163-170.

[5] QIN Nian -xiu, JIANG T ong, XU Chong-yu.TRENDS AND ABRUPTION ANALYSIS ON THE DISCHARGE IN THE YANGTZE BASIN[J].Resources and Environment in the Yangtze Basin,2005,05:589-594.

[6] Peng Meixiang, Xie Li, Chen Jing et al. Jing Wei River in recent 50 years in the middle reaches of the Yellow River distribution and its change characteristics of precipitation[J], Journal of Shannxi meteorology, 2003,01:19-23.

[7] Jiang yang, Sheng xiaodan, Sun lei. Based on Mann-Kendall and $\mathrm{R} / \mathrm{S}$ to analyze the annual runoff variation of Dahuofang Reservoir [J]. Northeast Water Resources and Electric Power. 2015,03:31-34.

[8] Jin Chen-hao, Han Jing-long. Analysis of precipitation Variation Trend and abrupt Change in Gaya River Basin Based on Mann-Kendall test [J]. Jilin Water Resources, 2013, $12: 62-66$
[9] Richarde Marques da Silva; Celso A. G. Santos; Madalena Moreira; Joo Corte-Real; Valeriano C. L. Silva; Isabella C. Medeiros. Rainfall and river flow trends using Mann-Kendall and Sen's slope estimator statistical tests in the Cobres River basin [J]. Natural Hazards. 2015,2:1205-1221.

[10] Shiqiang Du; Honghuan Gu; Jiahong Wen; Ke Chen; Anton Van Rompaey. Detecting Flood Variations in Shanghai over 1949-2009 with Mann-Kendall Tests and a Newspaper-Based Database [J].Water.2015, 5:1808-1824.

[11] Wang Shenxiong, Wei Hongyi, Zheng Xiaomei. Trend of runoff and mutation analysis in Weihe River basin [J].Water Resources Reserch, 2008,03:1-2.

[12] Jiao Jinyu, Wang Ning, Jia Jiangguo. characteristics and Abrupt Analysis of Climate Changes During Last 50 Years in Jiuquan City[J]. Journal of Ningxia University (Natural Science Edition), 2013, 4:375-380.

[13] Hamed, Khaled H.1.Trend detection in hydrologic data: The Mann-Kendall trend test under the scaling hypothesis. [J].Journal of Hydrology. 2008(No.3-4).

[14] Xu Zongxue, Zhang Nan. Analysis of the changing trend of precipitation in the Yellow River basin in recent 50 years [J]. geography Research, 2006, 01:27-34.

[15] Huang Zhiyang. The tendency variation of hydrological time series analysis method and related issues [J] Pearl River in Modern Construction, 2013, 03:4-5.

[16] Jiang Jianjun. Carrying forward the Weihe River water culture to promote basin harmonious development of society. [J] Shannxi Water Resources, 2008, 01:38-41.

[17] CAO Jieping, CHI Daocai, WU Liqiang et al. Mann-Kendall Examination and Application in the Analysis of Precipitation Trend[J].Agriculture Science \& Technology and Equipment, 2008,05:5-37.

[18] Sheng Yue, Paul Pilon, George Cavadias. Power of the MannKendall and Spearman's rho tests for detecting monotonic trends in hydrological series [J]. Journal of Hydrology, 2002, 2:591.

[19] Ijaz Ahmad, Deshan Tang, Tian Fang Wang, Mei Wang, Bakhtawar Wagan, Harry D. Kambezidis. Precipitation Trends over Time Using Mann-Kendall and Spearman's rho Tests in Swat River Basin, Pakistan [J]. Advances in Meteorology, 2015, 2015.

[20] ZHAN Chesheng, QIAO Chen, Xu Zongxue et al. CLIMATE CHANGE AND MUTATION ANALYSIS INWEIHE RIVERBASIN IN THE LAST 50 YEARS [J]. Journal of BeiJing Normal University (Natural Science), 2012, 04:399-405.

[21] LIU Juan, CHEN tao-tao, CHI Dao-cai. Rainfall Trend Analysis of the Northwest Liaoning Province Based on Daniel and Mann-kendall Test [J]. Journal of Shenyang Agricultural University, 2014, 05:599-603. 